\title{
Significant Dietary Changes during Human Evolution and the Development of Cancer: From Cells in Trouble to Cells Causing Trouble
}

\section{Wolfgang Kopp*}

Former head of the Diagnostikzentrum Graz, Mariatroster Str. 41, 8043 Graz, Austria

*Corresponding author: Wolfgang Kopp, Mariatroster Str. 41, 8043 Graz, Austria, Tel: +436641273210; E-mail: w.kopp@weiz.cc

Received date: June 19, 2017; Accepted date: August 7, 2017; Published date: August 14, 2017

Copyright: (c) 2017 Kopp W, This is an open-access article distributed under the terms of the Creative Commons Attribution License, which permits unrestricted use, distribution, and reproduction in any medium, provided the original author and source are credited.

\begin{abstract}
In all western societies, mortality rates from cancer are high and even increasing. In striking contrast, cancer rates are very rare and even non-existent in primitive cultures, like hunter-gatherer (HG) populations. HGs are free of disease as long as they adhere to their traditional low-insulinemic "Paleolithic" nutrition. With acculturation and transition to current high-carbohydrate/high-insulinemic "Western" diets (HCHIDs), cancer develops in high rates. This paper follows the question of how significant nutritional changes, brought about by the Agricultural revolution, may cause development of cancer. The evidence presented shows that the switch from a Paleolithic to a Western nutrition has brought about significant metabolic perturbations, like an abnormally increased activation of the insulinlike growth factor system, the sympathetic nervous system and the renin-angiotensin-system, an increased expression of HIF-1 $\alpha$ and other more, all of which are deeply involved in cancer development through promotion of proliferation, angiogenesis, inflammation, macrophage infiltration, metastasis and inhibition of apoptosis.
\end{abstract}

In addition, HCHIDs generate oxidative stress which may cause mitochondrial damage and genomic instability, and may interfere with normal stem cell development. Faulty redox signaling is suggested to play a significant role in cancer development: hydrogen peroxide, generated at low concentrations, represents an important chemical mediator in the regulation of various cellular signal transduction processes, including stem cell development. Oxidative stress may be sensed by cells as redox signaling. Faulty "redox signaling" is proposed to affect normal stem cell development by sustained activation of uncoupling protein 2, leading to inhibition of differentiation ("maturation arrest"), sustained uncontrolled proliferation, and glycolysis with high expression of hexokinase II, typical features of cancer. In summary, an abnormal diet-related activation of various metabolic systems, together with faulty redox signaling, is suggested to play a pivotal role in cancer development.

Keywords: Carcinogenesis; High-carbohydrate nutrition; Insulin resistance; Oxygen reactive species; Uncoupling protein; Redox signaling

\section{Abbrevations \\ ANG II: Angiotensin II; AT1R: Angiotensin II receptor type 1; CSC: Cancer stem cell; FADH: Flavin adenine dinucleotide; FFA: Free fatty acids; H2O2: Hydrogen peroxide; HCHID: High-carbohydrate/high- insulinemic diet; HG: Hunter-gatherer; HIF-1a: Hypoxia-inducible factor 1a; HOMA: Homeostasis model assessment; hPSC: Human pluripotent stem cell; IGF: Insulin-like growth factor; IR: Insulin resistance; LCLID: Low-carbohydrate/low-insulinemic diet; LGA: Large-for-gestational-age; NADH: Nicotinamide adenine dinucleotide hydrogen; NE: Norepinephrine; NOX: NADH oxidase; OXPHOS: Oxidative phosphorylation; RAS: Renin-angiotensin system; ROS: Reactive oxygen species; SC: Stem cell; SGA: Small-for-gestational-age; SNS: Sympathetic nervous system; UCP: Uncoupling protein}

\section{Introduction}

In all western societies, mortality rates from cancer are high and even increasing. At present, cancer is second only to cardiovascular disease as a cause of death [1]. In striking contrast, historical records of explorers, adventurers and frontiersmen as well as medical and anthropological reports indicate that cancer rates are very rare and even non-existent in primitive cultures [2-14]. Several reports and studies on the Inuit show that-prior to acculturation and adoption of a „Western” diet-people were virtually free of cancer [6-8]. Vilhjamur Stefansson [9] reports about the search of George Leavitt, a physician, for cancer among the Inuit of Canada and Alaska. It took him nearly 50 years, from 1884 to 1933 , to find a case of cancer. Similarly, an article on Eskimo health in The Canadian Medical Association Journal from May of 1936 reports: "In the Western Arctic Dr. Urquhart has as yet not met with a single case of cancer in the seven years of his practice. Cancer must be extremely rare in the Eastern Arctic also" [10].

The reported absence of cancer in hunter-gatherer societies is not restricted to the Inuit. Several other have reported on an astonishing low incidence or absence of cancer in "primitive" cultures, like the Australian aborigines and the aboriginal peoples of Africa and the Melanesian Islands [4,11-14]. The famous medical missionary, Dr. Albert Schweitzer, is quoted in Berglas [11] as follows: "On my arrival in Gabon, in 1913, I was astonished to encounter no cases of cancer. I saw none among the natives two hundred miles from the coast. I cannot, of course, say positively there was no cancer at all, but, like other frontier doctors, I can only say that if any cases existed they must have been quite rare".

Cancer (as well as other diseases of civilization, including coronary heart disease, obesity, hypertension, type 2 diabetes, autoimmune disease, osteoporosis, and other more) are rare or absent among 
hunter-gatherer (HG) societies, as long as these peoples adhere to their traditional diet. However, with transition to a high-carbohydrate/highinsulinemic "Western style" diet (HCHID), whether by migration or acculturation, invariably leads to a dramatic increase in this disease(s) [14-18]. In the Inuit, cancer incidence increased steadily through the $20^{\text {th }}$ century; meanwhile the circumpolar Inuit and Athabaskan/Dene have rates for several cancer sites that exceed all other regions in the world $[15,17,19]$. Similar developments apply to many other huntergatherer societies $[15,20]$.

The notion that Stone Agers usually didn't live long enough to get cancers is not accurate. Average life expectancy in hunter-gatherer societies is lower than in most acculturated societies today, which largely is attributed to higher rates of infant and child mortality and a lack of medical assistance. But once these people reach adulthood, their life expectancy is comparable to that of affluent nations. A conspectus of data on hunter-gatherer societies suggests that modal age of adult death is about seven decades (adaptive life span of 68-78 years). In contrast to most westerners, these people tend to be healthy up to old age. Causes of death are predominantly infectious diseases, while chronic degenerative disorders are rare [21].

Etiology and pathomechanism of cancer development are still under debate. While the somatic mutation theory has been the prevailing one in cancer research for the last 50 years, a body of evidence has accumulated showing that cancer is not only a genetic disease of uncontrolled cell proliferation, but also a metabolic disease [22-24]. Several risk factors for cancer development have been identified, most important smoking [25], age [26] and obesity (including comorbidities like type II diabetes and cardiovascular diseases) [27].

This paper presents evidence that fundamental dietary change during human history cause significant metabolic perturbations, related to the malignant process. A novel hypothesis is postulated that links carcinogenesis to HCHIDs.

\section{Human Evolution and Nutrition}

During the Paleolithic Period, from approximately 2,5 million years ago until the Agricultural Revolution about 10,000 years ago, our ancestors subsisted on diets containing large amounts of protein and varying amounts of fat (depending on the latitude), and relatively small amounts of (digestible) carbohydrate. Their diet was based chiefly on wild game, fish and uncultivated plant food high in fiber, like tubers, wild herbs, roots, berries, nuts, vegetables, fruits (and occasionally some honey), but not on cereals.

One of the major differences between hunter-gatherer diets and our "modern" nutrition concerns the Glycemic and Insulinogenic Index [28]: wild plants are fibrous and are therefore slowly digested, much of the carbohydrate is unavailable, and the carbohydrate content is therefore lower than that of their cultivated equivalents [29]. Hence, carbohydrates, consumed during this period were low-glycemic in effect [30], eliciting a low insulin response only [31]. Since the effect of protein and fat on insulin production is small too [32], postprandial glucose and insulin levels were low during a very long time of human evolution.

Living organisms thrive best on the diet to which they are evolutionarily adapted. The human genome has formed during a period of several million years and the DNA has remained largely unchanged during the past 10,000 years [33], thus, human metabolism is still adapted to the low-glycemic and low-insulinogenic diet of our Paleolithic ancestors.

The Agricultural Revolution about 10,000 years ago brought about a significant increase in dietary carbohydrate in the form of cereals and legumes. Progresses in food processing during the Industrial Revolution about 250 years ago resulted in a significant increase in the Glycemic and Insulinemic Index of refined cereals. In addition, cow milk (and other dairy products) also produce high postprandial insulin levels (despite a low-glycemic effect), not significantly different from the Insulinemic Index of the reference bread $[34,35]$. The switch from a low-carbohydrate/low-insulinemic "Paleolithic" diet (LCLID) to HCHIDs has broughtabout substantial adverse metabolic alterations and perturbations that may promote malignant transformation.

\section{HCHIDs and Insulin Resistance}

Insulin resistance (IR), obesity and the metabolic syndrome have risen dramatically in all westernized populations during the last decades [36], and the syndrome meanwhile is increasing also in developing countries [37]. Furthermore, peripheral insulin sensitivity as well as glucose tolerance decreases in westernized populations with advancing age. Both, fasting and postprandial glucose concentrations are higher in elderly than in young subjects $[38,39]$.

In contrast, low serum insulin levels and a persisting excellent insulin sensitivity is characteristic of HGs, and diseases of IR are rare or absent, as long as they adhere to their traditional low-carbohydrate diet and their ancestral life style [14,16,40-43]. But with acculturation and transition to a westernized lifestyle, especially to high-insulinemic diets, these populations develop high prevalence rates of hyperinsulinemia, IR and the metabolic syndrome [31,41,44-46]. Otherwise, a reversion to traditional low-insulinemic nutrition is accompanied with marked improvement of IR and fasting insulin levels $[44,47,48]$.

There is a widespread acceptance in the literature that obesity causes IR and compensatory hyperinsulinemia, but this assumption is not convincing [49]. In this regard, it also has to be considered that not all obese individuals are insulin resistant while IR has been shown to exist also in a significant proportion of the normal weight population [50].

Meanwhile, substantial evidence has accumulated indicating that hyperinsulinemia represents the driving force in the development of IR and precedes the development of IR as well as of obesity [35,51-53]. As shown by a whole range of experimental studies in animals [54-56] and in humans [35,57-60], a sustained elevated level of insulin, immaterial of its origin, represents the key factor for the development of IR [61]. Hyperinsulinemia was shown to impair insulin-stimulated glucose uptake and its cellular signaling in a dose-dependent manner $[62,63]$. Moderate hyperinsulinemia decreases insulin receptor numbers, with development of moderate IR; severe IR has been suggested to result from a combination of decreased insulin receptor numbers and a post-receptor defect [63]. An (insulin-induced) increased gene expression of proinflammatory cytokines in adipocytes [64], as well as metabolic inflexibility [65], ectopic lipid accumulation [65] and increased reactive oxygen species (ROS) production $[65,66]$ have been implicated in the developmental process. Depending on the individual texture of the $\beta$ cells, hyperinsulinemia and insulin resistance may develop rapidly, or increase gradually with increasing age. 
Hyperinsulinemia also appears to be involved in the development of obesity by overstimulating white adipose tissue and liver metabolic activity [52-54,67-71]. Several studies provide evidence that weight gain occurs prior to the development of IR. Postprandial hyperinsulinemia has been shown to represent the very first metabolic abnormality in developing obesity, while fasting insulin levels and insulin sensitivity are normal [35,52-54]. In a study by Sigal et al. [70], high rates of weight gain occurred in individuals who presented with a high acute insulin response to glucose, and this effect was particularly manifested in insulin-sensitive individuals. Similarly, a study in Pima Indians revealed that the relatively most insulin sensitive individuals had a greater tendency towards weight gain than the most insulin resistant ones [71]. IR (with compensatory hyperinsulinemia) develops later during the course of chronic obesity [52,70] and limits further weight gain $[53,71,72]$. HCHIDs elicit a high postprandial insulin response. Along with a "Western dietary pattern" of frequent snacking and frequent consumption of sucrose-containing soft drinks, insulin levels are elevated for most part of the day [37]. Pancreatic B-cells, genetically not adapted to this high insulin demand, may react with hypertrophy, functional dysregulation, and finally overresponsiveness and hyperinsulinemia [73,74]. Further, it is important to consider that high-carbohydrate diets are less satiating, while a higher protein intake increases satiety and leads to a reduced subsequent energy intake [75]. Consequently, restriction of carbohydrate intake has been shown to spontaneously reduce caloric intake and decrease hunger [76].

\section{Insulin Action during Pregnancy: Early Onset of IR and Cancer Risk}

Birth weight has been positively correlated with cancer risk [77]. Maternal diet composition has a significant impact on birth weight, as the following lines will prove.

During the course of pregnancy, beginning around the tenth week, a physiologic (transient) profound IR develops. Following delivery, IR abates [78-79]. Brand-Miller and Colagiuri [80] proposed that IR during gestation represents a genetic adaptation to the inherent low glucose content of LCLIDs our ancestors subsisted on during a very long period of human evolution, in order to reduce glucose consumption of the maternal tissues and spare glucose for the developing fetus.

Current HCHIDs "collide" with this hereditary adaptation. Diets high in rapidly digested and absorbed foods induce high maternal blood sugar levels. While glucose uptake by insulin-dependent maternal tissues is diminished, glucose can freely cross the placenta. Since insulin is not able to cross the placenta, the fetal pancreas is forced to produce large amounts of insulin. The degree of maternal IR as well as of its compensatory hyperinsulinemia mainly determines nutrient flux from mother to fetus and therefore influences birth weight. This has been confirmed in several studies, for instance in a retrospective observational study evaluating the association between the degree of maternal IR and neonatal birth weight in uncomplicated pregnancies: in non-diabetic, non-obese pregnant women, postprandial insulin levels as well as HOMA-IR were found to be positively correlated with birth weight and the risk of giving birth to a large-for-gestational-age (LGA) infant [81]. Also, a longitudinal study on nondiabetic, non-obese pregnant women revealed a significant correlation of postprandial blood glucose levels with fetal growth [82]. The metabolic alterations described are especially pronounced in maternal obesity [83] and gestational diabetes $[84,85]$.
According to Pedersens hyperglycemia-hyperinsulinism hypothesis [86], excessive maternal glucose crossing the placenta causes fetal hyperglycemia and hyperinsulinemia. Fetal hyperinsulinemia, plus a large supply of glucose substrate greatly enhances protein, lipid and glycogen synthesis, thereby promoting growth and adiposity $[83,87,88]$ and may cause $B$-cell hyperplasia [88], development of intrauterine IR [89-91] and IR during childhood [92]; increased IR and oxidative stress are already present in prepubertal normal-weight, small-forgestational-age (SGA) and LGA infants [92]. In addition, high plasma norepinephrine values were found in infants of diabetic mothers [93].

An interesting finding was reported by Neufeld et al. [94,95]: monocytes [94] as well as liver cells [95] of infants of diabetic mothers showed a significant increase in insulin receptor numbers as well as a greater binding capacity compared with normal infants, suggesting that the development of insulin receptors in embryonic cells/tissues is positively related to insulin levels, in contrast to downregulation in adult hyperinsulinemia.

\section{Birth Weight and Stem Cells-A Link to (Childhood) Cancer?}

Birth weight has been positively correlated with subsequent risk of childhood cancer as well as several cancer types in adults [77]. According to a "stem cell burden theory" [96], the in utero environment and perinatal factors may influence the size of the overall stem cell pool as well as birth-weight. The greater the stem cell pool size, the greater the risk that one of the stem cells will undergo malignant transformation in later life. The size of the stem cell pool in the developing fetus as well as birth weight are determined by the level of in utero/perinatal levels of growth factors and hormones, especially insulin and insulin-like growth factor 1 (IGF1); IGF1 is thought to increase the size of the stem cell pool; further, insulin itself is a growthpromoting hormone as well as the main regulator of fetal IGF 1 production $[97,98]$. It increases the bioactivity of IGF1 by directly enhancing hepatic IGF1 production [97] and by decreasing levels of IGFBP1 and IGFBP3 [98] which results in increased tissue availability of IGF1. In support of the theory, the umbilical cord blood concentrations of various hematopoietic stem and progenitor populations were shown to correlate with cord blood plasma levels of particular mitogens, especially IGF-1 [99], as well as with birth weight: a positive U-shaped correlation with high as well as low birth weight was noted [77].

Interestingly, a U-shaped relationship has also been observed between birth weight and IR in utero [89-91] and IR in childhood $[92,100]$.

In summary, diet composition influences the microenvironment of the fetus. High-insulinemic nutrition during pregnancy has the potential to exert significant influence on birth weight, insulin resistance in utero as well as in early childhood, the stem cell pool and cancer risk of the offspring later in life. In contrast, low-glycemic/ insulinemic diets are accompanied by lower insulin levels and lower birth weight $[83,101,102]$. Intriguingly, mean birth weight increased in the United States during the second half of the $20^{\text {th }}$ century [103]. This may reflect the increase in consumption of sucrose and highinsulinemic food during this period. 


\section{Insulin and Cancer}

The IGF system exerts a fundamental role in the regulation of cell growth and metabolism in response to nutrients and affects nearly every organ system in the body. The IGF system consists primarily of two ligands (IGF1 and IGF2, two cognate cell-surface receptors (IGF1R and IGF2R) and six IGF-binding proteins (IGFBP1 to IGFBP6). In addition to their endocrine properties, IGFs function also as paracrine (IGF1 and IGF2) and autocrine hormones (IGF1) and are produced by tumor cells [104]. The insulin receptor is activated by insulin, IGF-I and IGF-II. It has two isoforms, IR-A and IR-B. IR-A, predominantly expressed during prenatal life, enhances the effect of IGF-II during embryogenesis and fetal development. IR-A is often aberrantly expressed in cancer cells [105].

Suspicion about a possible role of insulin and the IGF system in carcinogenesis was raised by epidemiological studies that reported that obese individuals, especially those with type 2 diabetes, are at a higher risk of dying from cancers when compared with lean individuals without diabetes. In addition, the metabolic syndrome has been shown to be a major risk factor for cancer [106]. Hyperinsulinemia and IR have been implicated as a possible causal factor linking obesity and the metabolic syndrome to cancer [107]. Involvement of insulin, in particular hyperinsulinemia, as well as of the IGF system in malignancies is well documented [108]. Insulin itself is a growthpromoting hormone with mitogenic effects [97]. IGF1 as well as IGF2 are potent mitogens that play important roles in the promotion of cell proliferation, differentiation, metastasis and inhibition of apoptosis [109-113].

Furthermore, insulin and IGF1 inhibit hepatic synthesis of sexhormone binding globulin, while both hormones stimulate ovarian synthesis of sex steroids, which may promote cellular proliferation and inhibit apoptosis in breast tissue and endometrium [114].

Finally, IR and hyperinsulinemia are increasingly recognized as a low-grade inflammatory state associated with elevation of interleukin-6, adiponectin, leptin, tumor necrosis factor- $\alpha$, plasminogen activator inhibitor-1, monocyte chemoattractant protein and free fatty acids, which can play a role in malignant transformation and/or cancer progression [108]. The level of these inflammatory mediators has been shown to correlate with the degree of hyperinsulinemia [115]. Low-grade inflammation is widely prevalent in human cancer and may be a driver for p53 mutagenesis [116].

Epidemiological studies corroborate the adverse role of highinsulinemic nutrition, insulin and IR in the malignant state: high intake of sugar and refined carbohydrates and elevated blood glucose were found to be strongly associated with the risk of cancer [117] and with poorer survival after diagnosis for early breast cancer [118]. Also, chronic exogenous insulin therapy significantly increases the risk of colorectal cancer among type 2 diabetes patients [119]. In a clinical trial on breast cancer patients, IR was associated with a significantly worse prognosis [120].

\section{Sympathetic Nervous System (SNS) and Cancer}

The SNS is involved in the regulation of the microenvironment of virtually every major organ system of the body by releasing two catecholamine neuroeffector molecules, norepinephrine (NE) and epinephrine. NE is released primarily from the sympathetic nerves, while epinephrine is mainly secreted from the adrenal medulla. Both catecholamines act as neurotransmitters as well as circulating hormones. Adrenergic receptors are expressed on virtually every cell type in the body, including cancer cells [121].

It is well established that SNS activity is influenced by food ingestion: among dietary substrates, carbohydrate (starch and sugars) ingestion activates the SNS, characterized by a significant increase in plasma NE levels caused by spillover from sympathetic nerve endings $[122,123]$, while protein or fat ingestion exert minimal effects on NE levels only $[124,125]$. In feeding studies, high carbohydrate/protein diets were associated with a significant increase in NE levels, while high fat/protein diets did not alter SNS activity [124,125].

Insulin proved to be the link between carbohydrate intake and SNS activity $[126,127]$ and was shown to increase plasma NE levels in a dose-dependent fashion in normal man [127]. The reason for this dietinduced SNS activation is thought to be due to the vasodilatory effect of insulin: in normal humans, carbohydrate ingestion with its attendant physiologic insulinemia causes dilatation of the skeletal muscle vasculature, mediated chiefly by stimulation of nitric oxide release [128]. Activation of the SNS may then occur to offset an excessive fall in blood pressure as a result of generalized vasodilatation $[123,129]$.

In consideration of these facts there can be no doubt that the introduction of high-insulinemic food into human nutrition has brought about a new deleterious metabolic situation: a diet-related unphysiologically increased activity of the SNS [130], especially pronounced in obesity, where a sustained sympathetic activation, related to chronic hyperinsulinemia, has been detected [131].

At present, a growing body of evidence suggests that NE plays a pivotal role in the progression of malignant tumors by modulating proliferation, angiogenesis, inflammation, macrophage infiltration, metastasis and inhibition of apoptosis, mediated to some extent through activation of various growth factors and cytokines [132-135].

\section{Renin-Angiotensin-System (RAS) and Cancer}

The renin-angiotensin system (RAS) plays an important role in normal physiology as well as in pathologic conditions. Angiotensin II (ANG II) is the major effector peptide of the RAS. Insulin as well as IGF-I stimulate angiotensinogen production [136,137]. In addition, $\mathrm{NE}$ has been shown to stimulate renin secretion, thereby activating ANG II, while circulating ANG II interacts with the SNS at various sites and appears to amplify sympathetic activity [138]. It is meanwhile well established that in addition to the "classic" hormonal circulating system, a local RAS exists in various organs and tissues, leading to production of ANG II, with autocrine and paracrine effects [139].

ANG II has been recognized as a potent mitogen, and tumor cells frequently overexpress angiotensin II receptor type 1 (AT1R) [140,141]. Local expression of several components has been revealed to be involved in various cancer cells and tissues, including brain, breast, prostate, skin, lung, cervix and pancreatic carcinoma and glioblastoma [142]. Increasing evidence suggests that the RAS is linked to cancer through its ability to promote cell proliferation, tissue invasion, inflammation, angiogenesis and metastasis, immune suppression and pro-survival signaling [140,142-144].

Furthermore, the RAS is a key mediator of inflammation: the activation of AT1R has a powerful pro-inflammatory effect, promoting the expression of many pro-inflammatory mediators such as cytokines, chemokines and adhesion molecules [141]. The invasiveness and 
immunosuppression of many cancers appear to depend on inflammation and the upregulation of AT1R.

Also noteworthy, NE [145], the IGF system [146,147] as well as the RAS [148] increase the expression of the oxygen-responsive hypoxiainducible factor $1 \alpha$ (HIF-1 $\alpha$ ) which is deeply involved in cancer development, specifically in areas of vascularization and angiogenesis, energy metabolism, cell survival, and tumor invasion and metastasis [149].

In summary, the switch from LCLIDs to HCHIDs is associated with an abnormally increased activation of several metabolic systems related to the development of cancer (as well as other pathological processes). HCHIDs produce a metabolic situation that-inter aliapromotes proliferation and inhibits apoptosis. The next section shows that in addition, a (diet-induced) increased production of ROS (in especially hydrogen peroxide $\left.\left(\mathrm{H}_{2} \mathrm{O}_{2}\right)\right)$ and an increased activation of uncoupling protein 2 (UCP2) may play a central role in carcinogenesis.

\section{Mitochondria, Oxidative phosphorylation (OxPhos) and ROS Production}

The primary role of mitochondria is the generation of energy through OxPhos, and to regulate cellular metabolism. The tricarboxylic acid cycle oxidizes nutrients, yielding electrons in the form of reduced carriers $\mathrm{NADH}$ and $\mathrm{FADH} 2$ to the mitochondrial electron transport chain. The sequential transport of electrons from complex I or II to III and IV pumps protons across the inner membrane, thereby generating an electrochemical gradient. The final acceptor of electrons in the electron transport chain is reduction of molecular oxygen at complex IV, yielding water and ATP. ROS are an inevitable byproduct of the mitochondrial respiratory chain activity: some of the electrons transferred along the electron transport complex escape and reduce molecular oxygen to form a superoxide anion $\left(\mathrm{O}_{2}{ }^{-}\right)$ which is rapidly converted to $\mathrm{H}_{2} \mathrm{O}_{2}$ by superoxide dismutase [150]. In addition, ROS, produced by various sources, play a central role in cell signaling.

\section{Oxidative Stress and Counter Measures}

Significantly increased ROS production ("oxidative stress") may have deleterious effects on cells and mitochondria through damage of cellular macromolecules, including mitochondrial DNA (mDNA), protein and lipid. Mitochondria are protected by several countermeasures to mitigate oxidative stress, including glutathioneand thioredoxin-reducing system and carnitine acyltransferase enzymes [150], but these defenses are not perfect. Considering the fact that the mitochondrial genome, which encodes several OxPhos genes, is situated in close proximity to the electron transport chain, increased ROS production, overriding mitochondrial antioxidant defense, may cause mDNA mutations [151]. Since mDNA lacks the protective shields of histones and has limited DNA-repairing systems, mDNA damage may lead to a higher degree of mitochondrial dysfunction and, in turn, to higher ROS production, initiating a vicious cycle of ROS amplification [152] which may cause nuclear genomic instability $[23,153,154]$. Oxidative stress, with accumulation of damaged macromolecules, is considered the cause of mitochondrial dysfunction of aging [155].

In addition to the countermeasures described above, activation of UCPs has been implicated in decreasing ROS production [156]. At present, 5 UCP homologues (UCP1-5) have been identified in humans, with UCP2 being the most ubiquitous. While the main function of $\mathrm{UCP} 1$, situated in brown adipose tissue, is driving nutrient oxidation towards heat production instead of ATP generation, more recently identified homologs (UCP2-5) are not involved in thermogenesis but decrease the formation of mitochondrial ROS [152]. Expression of $\mathrm{UCP} 2$, the most ubiquitous protein, increases greatly in response to increased ROS production (in particular $\mathrm{H}_{2} \mathrm{O}_{2}$ ) [156-160]. Further, UCP2 is upregulated by hyperglycemia [161] and ANG II [162]. Expression levels of UCP2 are therefore often increased in pathological processes associated with oxidative stress, like obesity, diabetes, lipotoxicity, atherosclerosis, chronic inflammation, etc. [163].

\section{Stem Cell Metabolism and the Role of UCP2}

It is now largely clarified that UCP2 decreases ROS production by modifying mitochondrial substrate utilization. According to Bouillaud (164), UCP2 decouples OxPhos from glycolysis by inhibiting pyruvate (glucose) mitochondrial oxidation, and induces a metabolic shift that promotes glycolysis and therefore indirectly lowers the mitochondrial production of ROS. Consistent with this notion, a study on UCP2-/cells suggests that UCP2 promotes free fatty acid (FFA) and/or glutamine oxidation while limiting glucose-derived pyruvate oxidation in mitochondria [165] and is necessary for efficient oxidation of glutamine [166]. These findings are well in line with studies on the role of UCP2 in human pluripotent stem cells (hPSCs) $[167,168]$. Consequently, UCP2 is deeply involved in the regulation of energy metabolism, proliferation and differentiation of hPSCs. It is well established that stem cells heavily rely on glycolysis and use FFA and glutamine as the main energy source for OxPhos $[165,169,170]$. In stem cells, UCP2 inactivates the pyruvate dehydrogenase complex, thereby shunting substrates such as pyruvate away from glucose oxidation while promoting glycolysis, mediated by expression of high levels of hexokinase II $[167,170]$, and promotes oxidation of alternative substrates such as glutamine and free fatty acids (FFA) [165,170]. Inhibition of pyruvate entry into mitochondria, compensated by FFA and glutamine usage, prevents a non-reversible degradation of pyruvate to acetyl-CoA, thereby keeping the door open for utilization of pyruvate for anabolic purposes. With regard to high proliferation rates of stem cells, glycolysis may therefore be advantageous to provide intermediate metabolites like ribose and nicotine amide adenine dinucleotide reduced form (NADPH) from the pentose phosphate pathway to synthesize macromolecules, such as nucleic acids, lipids and proteins, required for anabolic metabolism and proliferation $[171,172]$.

With early differentiation, UCP2 is repressed and hPSC proliferation slows, glycolytic flux decreases dramatically and mitochondrial OxPhos, fueled by glucose and fatty acids, increases, indicating that glycolysis represents the preferred metabolic state of rapidly proliferating cells. UCP2 repression is necessary for full differentiation potential [167]. Ectopic UCP2 expression perturbs this metabolic transition, impairs hPSC differentiation, blocks glucose oxidation and promotes glycolysis and proliferation. Otherwise, UCP2 knockdown shifts hPSC bioenergetics towards glucose oxidation inhibits proliferation and promotes differentiation [165,167].

UCP2 seems to play an important role in carcinogenesis. UCP2 is well known to be overexpressed in cancer [152] and has been suggested to promote tumor development [157]. Overexpression of UCP2 was found in a variety of cancers, like in leukemia, ovarian, bladder, esophagus, testicular, colorectal, kidney, pancreatic, lung and prostate tumors [157]. Several studies have shown that UCP2 
overexpression is associated with increased proliferation, decreased ROS production [157,173,174] and resistance to apoptosis [173], whereas UCP2 silencing led to the induction of apoptosis and cell differentiation $[152,175]$.

\section{Embryo-Fetal Characteristics of Cancer}

Striking similarities exist between the energy metabolism of cancer cells and stem cells. As noted earlier, stem cells rely heavily on glycolysis, with high expression of hexokinase II, and use fatty acids and glutamine as the main energy source for OxPhos $[169,176]$. Similarly, cancer cells take up glucose and glutamine at high rates and convert glucose to lactate through aerobic glycolysis in the presence of oxygen ("Warburg effect"), with high expression of hexokinase II [177]. Glutamine as well as FFA oxidation is a major means of ATP production in transformed mammalian cells [178,179]. Like in stem cells, glycolysis may be advantageous for cancer cells by shunting glycolytic intermediates into amino acid, lipid and nucleotide synthesis for anabolic metabolism and proliferation [171,172]. While Warburg originally proposed that glycolysis in cancer cells was due to a permanent impairment of mitochondrial OxPhos, more recent investigations found that mitochondrial function is largely retained or at least not completely compromised in most cancers [171], and a majority of ATP is produced by oxidative phosphorylation [178]. It seems that the Warburg effect represents a physiologic genetic program that enables stem cells to provide large amounts of metabolites for proliferation, and (stem cell-derived) cancer cells use the same mechanism [180]. Ayyasami et al. [157] recently concluded that "the Warburg effect is mediated by UCP2 and UCP2 over-expression promotes tumor development".

A striking resemblance also exists between neoplastic and embryonic tissues as well as between several hallmarks of cancer and embryo-fetal development, including sustained proliferative signaling, self-sufficiency in growth signals, resistance to cell death, replicative immortality, angiogenesis and activation of invasion [181]. Significant similarities between embryonic stem cells and various cancers were found to also exist concerning gene expression as well as expression of alpha-fetoprotein [reviewed in 181].

For these and other reasons, like their ability to self-renew indefinitely and to differentiate into a variety of specialized cell types, stem cells (SCs) have been linked to cancer development already in the late 1970's; more recently, it has been suggested that cancer stem cells (CSC) (also called "tumor initiating cells") may be the driving force behind neoplastic transformation, cancer recurrence and metastasis $[182,183]$. The "cancer stem cell hypothesis" suggests that cancer is a stem cell disease and is based on the finding of cancer cells with the characteristics of adult stem cells in many human malignancies.

\section{Stem Cells or Retrodifferentiation of Differentiated Cells?}

While the CSC hypothesis suggests that CSC derive from the neoplastic transformation of normal stem cells from different origin [182], it does not imply that cancer is always caused by stem cells. Accordingly, CSC may arise from a stem cell, a progenitor cell, or a fully differentiated cell undergoing retrodifferentiation back to a stemlike state. Retrodifferentiation of differentiated cells has been defined as "a process of stepwise cell reversion (retrodifferentiation or retroprogrammation) leading, by division, mature or stem cells to progressive immaturity" [181]. Evidence for retrodifferentiation was provided by Chaffer et al. [184], studying cultures of normal and neoplastic mammary epithelial cells. They could demonstrate that normal, differentiated cells can spontaneously convert to a stem-like state without genetic manipulation. Increased activation of the IGF system, the SNS and the RAS supports the conversion of differentiated cells into stemlike cells, for instance through p53 inactivation [185] which makes cell reprogramming more efficient, or through increased expression of HIF- 1 a which plays a critical role during the induction of pluripotency by initiating a gene expression program which leads to a switch from OxPhos to glycolysis [186].

\section{Hydrogen Peroxide as Signaling Molecules}

While the majority of ROS are generated via the respiratory chain cascade as an inevitable byproduct, ROS are also generated intentionally (predominantly by $\mathrm{NADH}$ oxidases (NOX), but also by mitochondria $[187,188]$ as part of a signal transduction pathway in cellular response to various stimuli, like cytokines and growth factors, insulin, and ANG II [187]. Thus, in addition to the well-known pathophysiological effects of oxidative stress, ROS, produced at low concentrations, act as important chemical mediators in the regulation of signal transduction processes. In contrast to the superoxide anion and hydroxyl radical, the less reactive $\mathrm{H}_{2} \mathrm{O}_{2}$ is involved in various signal transduction pathways in normal as well as in cancer cells, including proliferation and differentiation [189,190,reviewed in 191] as well as inflammation, phagocytosis and apoptosis [192]. The mechanism of "redox signaling" involves the $\mathrm{H}_{2} \mathrm{O}_{2}$-mediated reversible oxidation of specific amino acids in enzymes and transcription factors, thereby altering their activities [187,193].

Under normal conditions, the generation of $\mathrm{H}_{2} \mathrm{O}_{2}$ is tightly controlled through an elaborate cellular antioxidant system, and the expression of these antioxidant enzymes is also tightly regulated, suggesting that the levels, localization, and/or activities of cellular antioxidants are important in determining biological responses to hydrogen peroxide [187]. Recent studies in mammalian cells have revealed that cell signaling depends on both, the concentration as well as on the mode of mitochondrial $\mathrm{H}_{2} \mathrm{O}_{2}$ production: in stem cells, increases in ROS production cause stem cell proliferation, differentiation, senescence, and apoptosis in a dose-dependent manner; low levels of ROS are required to maintain quiescence, a moderate increase may promote proliferation/differentiation, and a further increase can induce stem cell senescence or apoptosis [194]. Different levels and modes of $\mathrm{H}_{2} \mathrm{O}_{2}$ production can therefore induce distinct responses within a cell by activating different pathways [reviewed in 187]. As an example, the role of $\mathrm{H}_{2} \mathrm{O}_{2}$ in cardiovascular differentiation of embryonic stem cells is antagonistic: continuous exposure to ROS results in inhibition of differentiation, while pulsechase exposure to low-level ROS enhances differentiation [190]. Similarly, gene expression of the tumor suppressor p53 is different in response to different amounts of hydrogen peroxide: at low concentrations of hydrogen peroxide, the p53 transcription factor activates antioxidant genes that induce antioxidants, while higher amounts stimulate the expression of pro-oxidant target genes [195].

A body of evidence has accumulated demonstrating that, compared with their normal counterparts; many types of cancer cells are associated with increased levels of ROS. In addition to mitochondrial ROS production, growth factors and cytokines as well as inflammatory cells stimulate the production of ROS (in particular $\mathrm{H}_{2} \mathrm{O}_{2}$ ) in cancer (microenvironment) [196,197]. $\mathrm{H}_{2} \mathrm{O}_{2}$ is involved in various signal transduction pathways in cancer cells [190,191]. Furthermore, tumor 
Page 7 of 14

cells express increased levels of antioxidant proteins to detoxify from ROS, suggesting that a delicate balance of intracellular ROS levels is required for cancer cell function [197].

Increased ROS levels may play a significant role in cancer development by activating various signaling pathways [193,198]. Simply put, increased $\mathrm{H}_{2} \mathrm{O}_{2}$ values may be perceived as "redox signaling". It is tempting to assume, that abnormal "signaling" may interfere with normal stem cell development (which comprises proliferation, followed by differentiation). Activation of UCP2 plays a central role in this process by promoting glycolysis and proliferation ("stemness"), and inhibition of hPSC differentiation. As noted before, expression of UCP2 was found to increase greatly in response to elevated ROS production (in especially to $\mathrm{H}_{2} \mathrm{O}_{2}$ ) in vitro [157-160]. It is tempting to assume that continuous exposure of stem cells to (certain levels of) $\mathrm{H}_{2} \mathrm{O}_{2}$ may induce sustained $\mathrm{UCP} 2$ activation, resulting in inhibition of differentiation ("maturation arrest"), sustained uncontrolled proliferation, and glycolysis with high expression of hexokinase II, typical features of cancer. Maturation arrest has been implicated into cancer development before [199]. Based on the fact that malignant tumors frequently consist of a mix of undifferentiated cells and cells with a varying amount of differentiation (contributing to the well-known heterogeneity of cancer), the author suggested that the degree of differentiation of a carcinoma may depend "on the proportion of undifferentiated tumor stem cells, the stage of maturation arrest of the majority of cells in the tumor, and on the ability of some cells to escape arrest and to differentiate" [199]. Further, embryonic, fetal and neonatal antigens have been found in numerous malignant tumors, indicating that most, if not all, tumorassociated antigens are related to transitional stages of cell differentiation [183]. Varying levels of UCP2 expression may cause varying amounts of differentiation, thus contributing to heterogeneity of cancer.

Increasing evidence corroborates these hypothetical considerations: persistently upregulated $\mathrm{H}_{2} \mathrm{O}_{2}$-dependent signaling pathways have been shown to be involved in cell differentiation, growth and survival, as well as cell cycle arrest or apoptosis in many cancer cells. Several hallmarks of cancer can be directly linked to an increased ROS production, such as sustained proliferative signaling, activation of invasion and metastasis, induction of angiogenesis and resistance to cell death. Depending on its intracellular concentration and localization, $\mathrm{H}_{2} \mathrm{O}_{2}$ exhibits either pro- or anti-apoptotic activities [193,198]. Furthermore, neoplastic transformation is not an irreversible event: in experimental studies, carcinoma cells were induced to differentiate into normal mature cells and tissues $[181,199,200]$, supporting the notion that maturation arrest plays a pivotal role. In addition, alterations in redox signaling have been identified as a contributor to many disease processes, like IR, aging etc. [188].

In summary, ROS exert both positive and negative effects on cellular structures and metabolism. While low levels of hydrogen peroxide play an important role as signaling molecules involved in the regulation of many different biological processes including stem cell development, increased ROS production may cause damage to lipids, proteins and mDNA, and genomic instability, and may additionally interfere with normal stem cell development by abnormal activation of UCP2. The next section shows that HCHIDs may cause oxidative stress, and that oxidative stress may derive from several other sources, all of which represent well-known risk factors for cancer.

\section{Dietary Related Oxidative Stress}

It is well established that IR and obesity are associated with oxidative stress [201,202]. Excess supply of energy substrates in obesity and IR is believed to cause mitochondrial dysfunction and increased ROS production $[156,201,203,204]$. HCHIDs may be causally related to the production of oxidative stress, as the following section shows.

\section{Glucocentric and Adipocentric Metabolism}

The macronutrients carbohydrate, fat and protein are the primary catabolic substrates which provide humans with the bulk of energy. They are broken down into glucose, fatty acids and amino acids. Glucose and fatty acids serve as main fuels which can be oxidized in mitochondria for ATP production. Amino acids are used in body cells to form new proteins, or may be converted into glucose or stored as fat [205].

Dependent on diet composition, a "glucocentric" or an "adipocentric" metabolism develops, with significant differences regarding cell fuels and metabolic consequence. Low-carbohydrate diets, like the traditional diets of many hunter-gatherer societies, are associated with an adipocentric metabolism, while current "Western" high-carbohydrate diets are associated with a glucocentric metabolism. In an adipocentric metabolism, fatty acids serve as main fuel, while glucose is provided for glucose-dependent tissues only; in a glucocentric metabolism, glucose and fatty acids both serve as main fuels in a diurnal oscillating way [76].

LCLIDs are metabolically "uncomplicated". Since only one of the two main cell fuels is ingested in significant amounts, a clear-cut separation of cell fuels is sustained during feeding and fasting, $24 \mathrm{~h} /$ day. FFA or ketones serve as main fuel during the fed as well as the fasted state and are easily stored and released into circulation on demand. Glucose-dependent tissues (brain, red blood cells, retina, lens and renal medulla) receive glucose from ingested carbohydrate, supplemented, if necessary, through gluconeogenesis and glycogenolysis on demand. Diurnal oscillations in mitochondrial fuel selection between glucose and fatty acids are unnecessary. Postprandial insulin production is low and serves solely the fine tuning of blood sugar levels. Proteins serve as building blocks as well as energy sources. Very low carbohydrate diets as a variant (like the Inuit diet or ketogenic diet) lead to production of ketone bodies. These serve as the sole source of cellular energy production (except for red blood cells). Necessary amounts of glucose are provided through hepatic gluconeogenesis.

Human metabolism has (and still is) genetically adapted to this smoothly functioning and well balanced fuel utilization, with energy supply matched to demand.

In contrast, HCHIDs, containing high amounts of carbohydrates as well as substantial amounts of fat and protein are metabolically "demanding" because of a steady influx of competing fuels. Both, glucose as well as lipids, serve as cell fuels, competing for mitochondrial oxidization. Basically, mitochondria are able to switch freely between glucose and fatty acid oxidation in order to adjust fuel oxidation to fuel availability (termed as "metabolic flexibility"), but function smoothly only as long as acetyl-CoA is produced from one fuel at a time. Hence, this situation requires nutrient partitioning in order to avoid mitochondrial indecision and metabolic "gridlock" [203]. 
Nutrient partitioning is accomplished on a hormonal level through a temporary switch between glucose and fat utilization, mediated by the counter-regulatory hormones insulin and glucagon, both of which exert a strong influence on fat metabolism. During the fed state, a high insulin/glucagon ratio promotes lipid storage, while in the fasted state a high glucagon/insulin ratio stimulates lipolysis as well as hepatic glucose production to provide glucose supply to glucose-dependent tissues. Hence, during the fed state, glucose serves as the main fuel and fat is stored, while during the fasted state, fatty acids serve as main fuel and glucose is preserved for glucose-dependent tissues [76].

In addition, regulation of fuel selection occurs on a cellular level independent of hormonal mediation: The Randle Cycle adds an additional layer of metabolic "fine tuning" to the relative coarse hormonal regulation of nutrient utilization and storage. In 1963, Randle and coworkers [206] proposed a "glucose-fatty acid cycle" which describes the interplay between carbohydrate and lipid fuels in relation to the requirement for energy utilization and storage. According to the Randle cycle, utilization of one nutrient inhibits the use of the other directly, such that, on a cellular level, glucose consumption is suppressed when fat oxidation increases (and vice versa).

From an evolutionary perspective, a switch from a "one main fuel only" metabolism to a mix of competing fuels with necessity for a fedto-fasted fuel switch represents a new and potentially problematic situation, the human organism is not adapted to genetically. It needs well-functioning fuel partitioning to organize adequate mitochondrial fuel choice in response to nutritional circumstances.

As insulin controls systemic flux, storage and disposal of glucose, fatty acids and amino acids, insulin sensitivity is a prerequisite for this task [203]. Therefore, development of IR causes significant metabolic perturbations. With onset of IR, insulin-mediated suppression of fatty acid oxidation and of gluconeogenesis during the fed state is impaired and the genetic program, human metabolism has adapted to, retakes control: fatty acids are not stored sufficiently anymore and even released into circulation during the absorptive state, augmented by increased lipolysis, mediated by elevated norepinephrine levels [207]. $ß$-oxidation in muscle increases in the fed state in spite of sufficient or even increased amounts of glucose [208], accompanied by hepatic gluconeogenesis despite high glucose levels. Hence, the combined effect of HCHIDs and IR confronts all types of body cells with an increased mix of fuels, competing for mitochondrial oxidation.

\section{IR, Nutrient Excess, Mitochondrial Inflexibility and ROS}

At present, human physiology is characterized by overeating $[203,209]$, with a steady influx of cell fuels, aggravated by metabolic perturbations described above. Large amounts of fuels, taken up by cells and competing for mitochondrial oxidation, may lead to a faulty fuel choice and aberrant nutrient partitioning of various organs and cell types, a phenomenon termed as "metabolic inflexibility" [203]. Basically, OxPhos is a demand driven process where energy supply corresponds to energy demand. In a state of metabolic inflexibility, however, the overfed mitochondria continue to degrade an everlasting flood of different incoming carbon substrates (glucose, fatty acids and amino acids), with increased production of electron transfer donors (NADH and FADH2). When electron supply exceeds demand for ATP, proton re-entry through ATP synthase decreases and mitochondrial membrane potential rises, leading to an increased production of superoxide anions $\left(\mathrm{O}_{2}^{-}\right)$, followed by its rapid conversion to hydrogen peroxide by superoxide dismutase $[150,156]$. At high membrane potential, a small increase in membrane potential gives rise to production of significant amounts of ROS [210,211]. Nutrient excess and metabolic inflexibility are a major cause of increased mitochondrial ROS production and oxidative stress [156,203,212]. These perturbations of blunted fuel switching and distorted nutrient sensing have been described in a variety of clinical settings, including obesity and diabetes, as well as in various organs and cell types, like adipose tissues, macrophages and monocytes [203].

In addition, nutrient excess has the potential to cause mitochondrial dysfunction and increased ROS production through adverse effects on the mitochondrial life cycle which is characterized by continuous transitions between elongation (connected state) and fragmentation (separated state). Disabling these brief transitions between connected and separated mitochondria arrests the life cycle, compromises mitochondrial quality control and may lead to accumulation of damaged mitochondria that cannot be segregated [156,213]. Prolonged nutrient excess leads to fragmentation and inhibition of the mitochondrial life cycle and autophagy, and ultimately to mitochondrial damage and an increase in ROS generation. Hyperglycemia, as an example, has been shown to cause increased production of mitochondrial ROS, associated with dynamic changes in mitochondrial morphology in the form of rapid fragmentation [214]. According to Liesa [156], these alterations may explain different reports, demonstrating mitochondrial dysfunction in pathologies associated with an imbalance in nutrient supply and demand, like obesity and diabetes.

The opinion that cancer could be a diet-related disease has already been expressed earlier: Wellen et al. [215] proposed that nutrient excess may play a role in carcinogenesis through hyperinsulinemia, chronic low-grade inflammation and ROS-mediated mutagenesis of DNA.

\section{Cancer Risk Factors and Related Metabolic Alterations}

Intriguingly, the most important risk factors for cancer development are associated with increased ROS production and frequently with insulin resistance.

Ageing: Advancing age is a high risk factor for cancer, with persons over 65 accounting for $60 \%$ of newly diagnosed malignancies and $70 \%$ of all cancer deaths [26].

Aging is associated with a whole series of metabolic alterations related to the development of cancer, like increased ROS production and damage to mitochondria with mitochondrial dysfunction (including stem cells) $[155,212,216]$, insulin resistance and hyperinsulinemia including activation of the IGF system [39], glucose intolerance [38], increased SNS activity [217], and a progressive increase in total body fat in the general population with advancing age [218].

Obesity: Obesity is associated with systemic oxidative stress [201,202], mitochondrial dysfunction [204], expression of UCP2 [219], IR and hyperinsulinemia [54,70,73], and increased SNS activity [220].

Smoking: Smoking has been implicated in cancer development through its mutagenic effects.

However, smoking is also associated with systemic oxidative stress [202], mitochondrial damage and dysfunction, increased SNS activity 
and NE turnover [222], and has been suggested to cause IR and hyperinsulinemia $[223,224]$.

Inflammation: Many cancers arise from sites of chronic irritation, infection, or inflammation which also represents sites associated with increased stem cell activity. The finding that chronic inflammation is accompanied by the copious production of ROS supports the concept that oxidative stress induced by chronic inflammation could mediate neoplastic transformation of stem cells [193].

Growth factors and cytokines as well as inflammatory cells like neutrophils and macrophages stimulate the production of ROS [197]. In addition, inflammation induces cell proliferation, and this inflammation-induced cell proliferation potentiates DNA damageinduced mutations [225]. Inflammation is frequently associated with IR [64,226], like for instance in chronic bowel disease [226].

Viruses: Viral infections may be associated with mitochondrial dysfunction and increased production of ROS [227,228]. Hepatitis C virus, for instance, has been reported to cause hepatocellular carcinoma, at least in part through oxidative stress, inflammatory response and insulin resistance-related mechanisms [108].

\section{Summary and Suggested Pathomechanism (Figure 1)}

The evidence presented shows that the switch from a Paleolithic to a "Western" nutrition has brought about significant metabolic perturbations that may cause malignant transformation, like an abnormal activation of metabolic systems like the IGF system, the SNS and the RAS, an increased expression of HIF-1a, and other more, all of which are deeply involved in cancer development and well known to promote proliferation as well as angiogenesis, inflammation, macrophage infiltration, metastasis and inhibition of apoptosis.

Furthermore, HCHIDs generate oxidative stress which may cause mDNA damage and genomic instability, and may interfere with normal stem cell development. Faulty redox signaling is suggested to play a significant role in cancer development. Hydrogen peroxide, generated at low concentrations, represents an important chemical mediator in the regulation of various cellular signal transduction processes including stem cell development. Oxidative stress may be sensed by cells as redox signaling. This abnormal "signaling" may interfere with normal stem cell development through sustained UCP2 activation, resulting in inhibition of differentiation ("maturation arrest"), sustained uncontrolled proliferation, and glycolysis with high expression of hexokinase II, typical features of cancer. Faulty signaling may also affect other aspects, like for instance aberrant p53 expression. While it is likely that most of the transformed cells will undergo apoptosis, some will not.

As far as the findings of Neufeld et al. [94,95] are concerned - the number of insulin receptors correlated positively with the insulin level during fetal development - it is tempting to assume that receptor expression in the developing embryo (and in stem cells?) generally correlates positively with ligand levels. If this were the case, it could provide an explanation for the well-known receptor upregulation in cancer (including upregulation of the antioxidant system?).

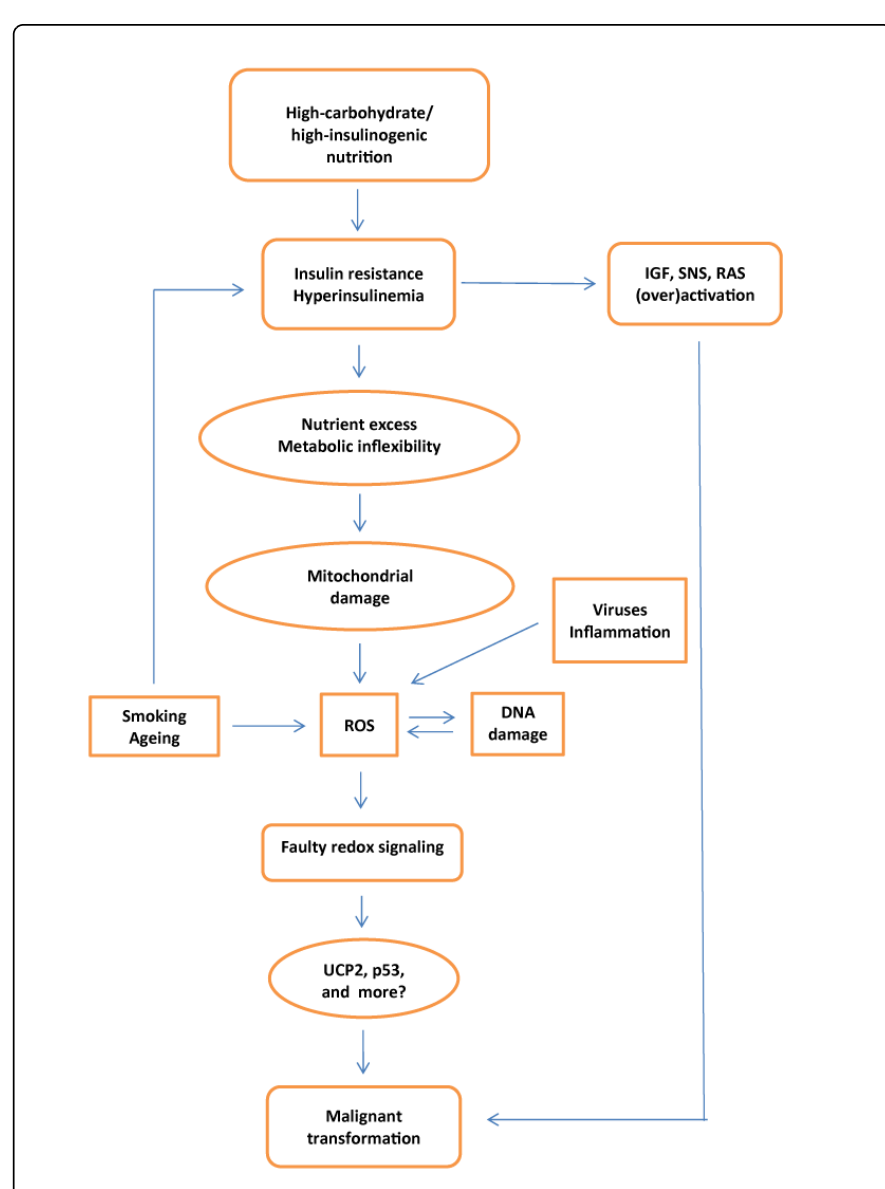

Figure 1: Suggested patho mechanism.

In summary, an abnormal diet-related activation of various metabolic systems, together with faulty redox signaling, is suggested to play a pivotal role in cancer development. The proposed pathomechanism is able to elucidate several characteristics of cancer development which currently do not have a sufficient explanation, like for instance the association between cancer and the metabolic syndrome, the increasing prevalence of cancer during the past century, and the Warburg effect.

\section{References}

1. Yancik R, Holmes ME (2002) Exploring the Role of Cancer Centers for Integrating Aging and Cancer Research.

2. Bulkley JL (1927) Cancer among primitive tribes. Cancer 4: 289-295.

3. Riveros M (1970) First observation of cancer among the Pampido Indians of the Paraguayan Chaco. Int Surg 53: 51-55.

4. Hearsey $\mathrm{H}$ (1906) The rarity of cancer among the aborigines of British Central Africa. Br Med 1: 1562-1563.

5. Dewailly E, Mulvad G, Sloth Pedersen H, Hansen JC (2003) Inuit are protected against prostate cancer. Cancer Epidemiol Biomarkers Prev 12: 926-927.

6. Shephard RJ, Rode A (1996) The health consequences of "modernization": evidence from circumpolar peoples, Cambridge University Press Cambridge: United Kingdom.

7. Schaefer O (1973) The changing health picture in the Canadian North. Can J Ophtalmol 8: 196-204. 
8. Hildes JA, Schaefer O (1984) The changing picture of neoplastic disease in the western and central Canadian Arctic. Can Med Assoc 130: 25-32.

9. Stefansson V (1960) Cancer: Disease of Civilization? Hill and Wang, New York. pp: 135.

10. Urquhart JA (1935) The most northerly practice in Canada. Can Med Assoc J 33: 193-196.

11. Berglas A (1957) Cancer: Nature, Cause and Cure. Institute Pasteur, Paris. pp: $27-58$.

12. Williams WR (1908) The Natural History of Cancer. William Wood and Company, New York.

13. Henson, WW (1904) Cancer in Kafirs: suggested cause. Guy's Hospital Gazette 26: 131-133.

14. Lindeberg S, Eliasson M, Lindahl B, Ahrén B (1999) Low serum insulin in traditional Pacific Islanders -the Kitava Study. Metabolism 4: 1216-1219.

15. Eaton SB, Konner M, Shostak M (1988) Stone agers in the fast lane: chronic degenerative diseases in evolutionary perspective. Am J Med 84 739-749.

16. Carrera-Bastos P, Fontes-Villalba M, O'Keefe JH (2011) The western diet and lifestyle and diseases of civilization. Res Rep Clin Cardiol 2: 15-35.

17. Schaeffer O (1971) When the Eskimo comes to town. Nutr Today 6: 8-16.

18. Trowell HC (1980) From normotension to hypertension in Kenyans and Ugandans. East Afr Med J 57: 167-173.

19. Young TK, Kelly JJ, Friborg J, Soininen L, Wong KO, et al. (2016) Cancer among circumpolar populations: an emerging public health concern. Int $\mathrm{J}$ Circumpol Health 75: 10.

20. Renner W (1910) The spread of cancer among the descendants of the liberated Africans or Creoles of Sierre Leone. Brit Med J 2: 587-589.

21. Gurven M, Kaplan H (2007) Longevity among hunter-gatherers: a crosscultural examination. Popul Dev Rev 33: 321-365.

22. Coller HA (2014) Is Cancer a Metabolic Disease? Am J Pathol 184: 4-17.

23. Seyfried TN, Shelton LM (2010) Cancer as a metabolic disease. Nutr Metab 7: 7 .

24. DeBerardinis RJ, Lum JJ, Hatzivassiliou G, Thompson CB (2008) The biology of cancer: metabolic reprogramming fuels cell growth and proliferation. Cell Metab 7: 11-20.

25. Centers for Disease Control and Prevention (US); National Center for Chronic Disease Prevention and Health Promotion (US); Office on Smoking and Health (US) (2010) How Tobacco Smoke Causes Disease: The Biology and Behavioral Basis for Smoking-Attributable Disease: A Report of the Surgeon General. Atlanta (GA): Centers for Disease Control and Prevention (US).

26. Berger NA, Savvides P, Koroukian SM, Kahana EF, Deimling GT, et al (2006) Cancer in the Elderly. Trans Am Clin Climatol Assoc 117: 147156.

27. Sartorius B, Sartorius K, Aldous C, Madiba TE, Stefan C, et al. (2016) Carbohydrate intake, obesity, metabolic syndrome and cancer risk? A two-part systematic review and meta-analysis protocol to estimate attributability. BMJ Open 6: e009301.

28. Ray KS, Singhania PR (2014) Glycemic and insulinemic responses to carbohydrate rich whole foods. J Food Sci Technol 51: 347-352.

29. Eaton SB, Konner M (1985) Paleolithic nutrition. A consideration of its nature and current implications. N Engl J Med 312: 283-289.

30. Bjork I, Liljeberg H, Ostman E (2000) Low glycaemic-index foods. Br J Nutr 83: 149-155.

31. Thorburn AW, Brand JC, O’Dea K, Spargo RM, Truswell AS, et al. (1987) Plasma glucose and insulin responses to starchy foods in Australian aborigines: a population now at high risk of diabetes. Am J Clin Nutr 46: 282-285.

32. Krezowski PA, Nuttall FQ, Gannon MC, Bartosh NH (1986) The effect of protein ingestion on the metabolic response to oral glucose in normal individuals. Am J Clin Nutr 44: 847-855.

33. Macaulay V, Richards M, Hickey E, Vega E, Cruciani F, et al. (1999) The emerging tree of West Eurasian mtDNAs: a synthesis of control-region sequences and RFLPs. Am J Hum Genet 64: 232-249.
34. Ostman EM, Liljeberg Elmståhl HG, Björck IM (2001) Inconsistency between glycemic and insulinemic responses to regular and fermented milk products. Am J Clin Nutr 74: 96-100.

35. Hoppe C, Mølgaard C, Vaag A, Barkholt V, Michaelsen KF, et al. (2005) High intakes of milk, but not meat, increases insulin and insulin resistance in 8-year-old boys. Eur J Clin Nutr 59: 393-398.

36. Sorrentino MJ (2005) Implications of the metabolic syndrome: the new epidemic. Am J Cardiol 96: 3E-7E.

37. Esmaillzadeh A, Kimiagar M, Mehrabi Y, Azadbakht L, Hu FB, et al. (2007) Dietary patterns, insulin resistance, and prevalence of the metabolic syndrome in women. Am J Clin Nutr 85: 910-918.

38. Fink RL, Kolterman OG, Griffin J, Olefsky JM (1983) Mechanism of insulin resistance in aging. J Clin Invest 71: 1523-1535.

39. Basu R, Breda E, Oberg AL, Powell CC, Dalla Man C, et al. (2003) Mechanisms of the age- associated deterioration in glucose tolerance: contribution of alterations in insulin secretion, action, and clearance. Diabetes 52: 1738-1748.

40. Brand JC, Snow BJ, Nabhan GP, Truswell AS (1990) Plasma glucose and insulin responses to traditional Pima Indian meals. Am J Clin Nutr 51: 416-420.

41. O'Dea K, White NG, Sinclair AJ (1988) An investigation of nutritionrelated risk factors in an isolated Aboriginal community in northern Australia: advantages of a traditionally-orientated life-style. Med J Aust 148: $177-180$.

42. Lindgärde F, Widén I, Gebb M, Ahrén B (2004) Traditional versus agricultural lifestyle among Shuar women of the Ecuadorian Amazon: Effects on leptin levels. Metabolism 53: 1355-1358.

43. Sinnett PF, Whyte HM (1973) Epidemiological studies in a total highland popula Tukisenta, New Guinea. Cardiovascular disease and relevant clinical, electrocardiographic, radiological and biochemical findings. J Chronic Dis 26: 265-290.

44. O'Dea K (1991) Westernization, insulin resistance and diabetes in Australian aborigines. Med J Aust 155: 258-264.

45. Wise PH, Edwards FM, Thomas DW, Elliot RB, Hatcher L, et al. (1970) Hyperglycemia in the urbanized Aboriginal. Med J Aust 28: 1001-1016.

46. Rowley KG, Best JD, McDermott R, Green EA, Piers LS, et al. (1997) Insulin resistance syndrome in Australian aboriginal people. Clin Exp Pharmacol Physiol 24: 776-781.

47. O'Dea K (1984) Marked improvement in carbohydrate and lipid metabolism in diabetic Australian aborigines after temporary reversion to traditional lifestyle. Diabetes 33: 596-603.

48. Rave K, Roggen K, Dellweg S, Heise T, Tom Dieck H, et al. (2007) Improvement of insulin resistance after diet with a whole-grain based dietary product: results of a randomized, controlled cross- over study in obese subjects with elevated fasting blood glucose. Br J Nutr 98: 929-936.

49. Karpe F, Dickmann JR, Frayn KN (2011) Fatty acids, obesity, and insulin resistance: time for a reevaluation. Diabetes 60: 2441-2449.

50. Reaven G (2005) All obese individuals are not created equal: insulin resistance is the major determinant of cardiovascular disease in overweight/obese individuals. Diab Vasc Dis Res 2: 105-112.

51. Corkey BE (2012) Banting lecture: hyperinsulinemia: cause or consequence? Diabetes 61: 4-13.

52. Le Stunff C, Bougneres P (1994) Early changes in postprandial insulin secretion, not in insulin sensitivity, characterize juvenile obesity. Diabetes 43: 696-702

53. Cusin I, Rohner-Jeanrenaud F, Terettaz J, Jeanrnaud B (1992) Hyperinsulinemia and its impact on obesity and insulin resistance. Int J Obes 16: S1-S11.

54. Penicaud L, Kinebanyan MF, Ferre' P, Morin J, Kande J, et al. (1989) Development of VMH obesity: in vivo insulin secretion and tissue insulin sensitivity. Am J Physiol 257: E255-E260.

55. Juan CC, Fang VS, Kwok CF, Perng JC, Chou YC, et al. (1999) Exogenous hyperinsulinemia causes insulin resistance, hyperendothelinemia, and subsequent hypertension in rats. Metab Clin Exp 48: 465-471. 
56. Ng Y, Ramm G, James DE (2010) Dissecting the mechanism of insulin resistance using a novel heterodimerization strategy to activate Akt. J Biol Chem 285: 232-239.

57. Rizza RA, Mandarino LJ, Genest J, Baker BA, Gerich JE, et al. (1985) Production of insulin resistance by hyperinsulinemia in man. Diabetologia 28: 70-75.

58. Del Prato S, Leonetti F, Simonson DC, Sheehan P, Matsuda M, et al (1994) Effect of sustained physiologic hyperinsulinemia and hyperglycemia on insulin secretion and insulin sensitivity in man. Diabetologia 37: 1025-1035.

59. Clark MG, Rattigan S, Clark DG (1983) Obesity with insulin resistance: experimental insights. Lancet 26: 1236-1240.

60. Ge X, Yu Q, Qi W, Shi X, Zhai Q, et al. (2008) Chronic insulin treatment causes insulin resistance in 3T3-L1 adipocytes through oxidative stress. Free Radic Res 42: 582-591.

61. Shanik MH, Xu Y, Škrha J, Dankner R, Zick Y, et al. (2008) Insulin resistance and hyperinsulinemia; Is hyperinsulinemia the cart or the horse? Diabetes Care 31: S262-S268.

62. Posa JK, Selvaraj S, Sangeetha KN, Baskaran SK, Lakshmi BS, et al. (2014) p53 mediates impaired insulin signaling in 3T3-L1 adipocytes during hyperinsulinemia. Cell Biol Int 38: 818-824.

63. Olefsky JM, Kolterman OG (1981) Mechanisms of insulin resistance in obesity and noninsulin-dependent (type II) diabetes. Am J Med 7: 151-168.

64. Pedersen DJ, Guilherme A, Danai LV, Heyda L, Matevossian A, et al. (2015) A major role of insulin in promoting obesity-associated adipose tissue inflammation. Mol Metab 4: 507-518.

65. Muoio DM, Neufer DP (2012) Lipid-induced mitochondrial stress and insulin action in muscle. Cell Metab 15: 595-605.

66. Montgomery MK, Turner N (2015) Mitochondrial dysfunction and insulin resistance: an update. Endocr Connect 4: R1-R15.

67. Templeman NM, Skovsø S, Page MM, Lim GE, Johnson JD, et al. (2017) A causal role for hyperinsulinemia in obesity. J Endocrinol 232: R173R183.

68. Mehran AE, Templeman NM, Brigidi GS, Lim GE, Chu KY, et al. (2012) Hyperinsulinemia drives diet-induced obesity independently of brain insulin production. Cell Metab 16: 723-737.

69. Erion KA, Corkey BE (2017) Hyperinsulinemia: a cause of obesity? Curr Obes Rep 6: 178-186.

70. Sigal RJ, EI-Hashimy M, Martin BC, Soeldner S, Krolewski AS, et al. (1997) Acute post-challenge hyperinsulinemia predicts weight gain: a prospective study. Diabetes 46: 1025-1029.

71. Swinburn BA, Nyomba BL, Saad MF, Zurlo F, Raz I, et al. (1991) Insulin resistance associated with lower rates of weight gain in Pima Indians. Clin Invest 88: 168-173.

72. Eckel RA (1992) Insulin resistance: an adaptation for weight maintenance. Lancet 340: 1452-1453.

73. Kopp W (2003) High insulinogenic nutrition-an etiologic factor for obesity and the metabolic syndrome? Metabolism 52: 800-804.

74. Mahler RJ (1981) The relationship between the hyperplastic pancreatic islet and insulin insensitivity in obesity. Acta Diabetol Lat 18: 1-17.

75. Veldhorst M, Smeets A, Soenen S, Hochstenbach-Waelen A, Hursel R, et al. (2008) Protein- induced satiety: Effects and mechanisms of different proteins. Physiol Behav 94: 300-307.

76. Westman EC, Feinman RD, Mavropoulos JC, Vernon MC, Volek JS, et al. (2007) Low-carbohydrate nutrition and metabolism. Am J Clin Nutr 86: 276-284.

77. Strohsnitter WC, Savarese TM, Low HP, Chelmow DP, Lagiou P, et al. (2008) Correlation of umbilical cord blood haematopoietic stem and progenitor cell levels with birth weight: implications for a prenatal influence on cancer risk. Brit J Cancer 98: 660-663.

78. Yen SSC, Jaffe R (1991) Endocrine metabolic alterations induced by pregnancy. In: Reproductive endocrinology. 3rd ed. W.B. Saunders Company, Philadelphia, London, Toronto. pp: 959-963.
79. Spellacy WN, Goetz FC (1963) Plasma insulin in normal late pregnancy. N Engl J Med 268: 988- 991.

80. Brand-Miller JC, Colagiuri S (1994) The carnivore connection: dietary carbohydrate in the evolution of NIDDAM. Diabetologia 37: 1280-1286.

81. Yamashita H, Yasuh I, Fukuda M, Kugishima Y, Yamauchi Y, et al. (2014) The association between maternal insulin resistance in mid-pregnancy and neonatal birthweight in uncomplicated pregnancies. Endocr J 61: 1019-1024.

82. Parretti E, Mecacci F, Papini M, Cioni R, Carignani L, et al. (2001) Thirdtrimester maternal glucose levels from diurnal profiles in nondiabetic pregnancies: correlation with sonographic parameters of fetal growth. Diabetes Care 24: 1319-1323.

83. Clapp JF 3rd (2002) Maternal carbohydrate intake and pregnancy outcome. Proc Nutr Soc 61: 45-50.

84. Kaaja R, Rönnemaa T (2008) Gestational diabetes: pathogenesis and consequences to mother and offspring. Rev Diabet Stud 5: 194-202.

85. Kopp W (2005) Role of high-insulinogenic nutrition in the etiology of gestational diabetes mellitus. Medical hypothesis 64: 101-103.

86. Pedersen J (1977) Hyperglycemia-hyperinsulinism theory and birth weight; In: Pedersen J, ed. The pregnant diabetic and her new-born. Williams and Wilkins, 2nd ed. Baltimore, Maryland.

87. Freinkel N (1980) Of pregnancy and progeny. Diabetes 29: 1023-1034.

88. Susa JB, Schwarz R (1985) Hyperinsulinemia in the primate fetus. Diabetes 34: 36-41.

89. Catalano PM, Presley L, Minium J, Hauguel-de Mouzon S, et al. (1964) Fetuses of obese mothers develop insulin resistance in utero. Diabetes 13: 278-285.

90. Simental-Mendía LE, Castañeda-Chacón A, Rodríguez-Morán M, Guerrero-Romero F (2012) Birth-weight, insulin levels, and HOMA-IR in newborns at term. BMC Pediatr 12: 94.

91. Yadav KK, Gupta R, Gupta A, Gupta M (2003) Insulin levels in low birth weight neonates. Indian J Med Res 118: 197-203.

92. Chiavaroli V, Giannini C, D'Adamo E, de Giorgis T, Chiarelli F, et al. (2009) Insulin resistance and oxidative stress in children born small and large for gestational age. Pediatrics 124: 695-702.

93. Young JB, Cohen WR, Rappaport EB, Landsberg L (1979) High plasma norepinephrine concentrations at birth in infants of diabetic mothers. Diabetes 28: 697-699.

94. Neufeld ND, Scott M, Kaplan SA (1980) Ontogeny of the mammalian insulin receptor. Studies of human and rat fetal liver plasma membranes. Dev Biol 78: 151-160.

95. Neufeld ND, Kaplan SA, Lippe BM (1979) Insulin binding studies in normal infants and infants of diabetic mothers. Pediatr Res 12: 397.

96. Ahlgren M, Wohlfahrt J, Olsen LW, Sørensen TIA, Melbye M, et al. (2007) Birth weight and risk of cancer. Cancer 110: 412-419.

97. Amiel SA, Sherwin RS, Hintz RL, Gertner JM, Press CM, et al. (1984) Effect of diabetes and its control on insulin-like growth factors in the young subject with type 1 diabetes. Diabetes 33: 1175-1179.

98. Frystyk J, Vestbo E, Skjaerbaek C, Morgensen CE, Orskov H, et al. (1995) Insulin-Like Growth Factors in Human Obesity. Metabolism 44: 35-44.

99. Savarese TM, Strohsnitter WC, Low HP, Liu Q, Baik I, et al. (2007) Correlation of umbilical cord blood hormones and growth factors with stem cell potential: implications for the prenatal origin of breast cancer hypothesis. Breast Cancer Res 9: R29.

100. Wei JN, Sung FC, Li CY, Chang CH, Lin RS, et al. (2003) Low birth weight and high birth weight infants are both at an increased risk to have type 2 diabetes among schoolchildren in Taiwan. Diabetes Care 26: 343-348.

101. Viana LV, Gross JL, Azevedo MJ (2014) Dietary intervention in patients with gestational diabetes mellitus: a systematic review and meta-analysis of randomized clinical trials on maternal and newborn outcomes. Diabetes Care 37: 3345-3355.

102. Louie JC, Markovic TP, Perera N, Foote D, Petocz P, et al. (2011) A randomized controlled trial investigating the effects of a low-glycemic 
index diet on pregnancy outcomes in gestational diabetes mellitus. Diabetes Care 34: 2341-2346.

103. Donahue SMA, Kleinman KP, Matthew W, Gillman MW, Oken E (2010) Trends in birth weight and gestational length among singleton term births in the United States 1990-2005. Obstet Gynecol 115: 357-364.

104. Brahmkhatri VP, Prasanna C, Atreya HS (2015) Insulin-like growth factor system in cancer: novel targeted therapies. Biomed Res Int 53: 8019.

105. Belfiore A, Frasca F, Pandini G, Sciacca L, Vigneri R, et al. (2009) Insulin receptor isoforms and insulin receptor/insulin-like growth factor receptor hybrids in physiology and disease. Endocr Rev 30: 586-623.

106. Esposito K, Chiodini P, Colao A, Lenzi A, Giugliano D, et al. (2012) Metabolic syndrome and risk of cancer: a systematic review and metaanalysis. Diabetes Care 3: 2402-2411.

107. Godsland FI (2010) Insulin resistance and hyperinsulinaemia in the development and progression of cancer. Clinical Science 118: 315-332.

108. Djiogue S, Nwabo Kamdje AH, Vecchio L, Kipanyula MJ, Farahna M, et al. (2013) Insulin resistance and cancer: the role of insulin and IGFs. Endocr Relat Cancer 20: R1-R17.

109. Boyd DB (2003). Insulin and Cancer. Integr Cancer Ther 2: 315-329.

110. Cory S, Vaux DL, Strasser A, Harris AW, Adams JM, et al. (1999) Insights from Bcl-2 and Myc: malignancy involves abrogation of apoptosis as well as sustained proliferation. Cancer Res 59: 1685s-1692s.

111. Parrizas M, LeRoith D (1997) Insulin-like growth factor-1 inhibition of apoptosis is associated with increased expression of the bcl-xL gene product. Endocrinology 138: 1355-1358.

112. Yu H, Rohan $\mathrm{T}$ (2000) Role of the insulin-like growth factor family in cancer development and progression. J Natl Cancer Inst 92: 1472-1489.

113. Gallagher EJ, LeRoith D (2011) Minireview: IGF, Insulin, and Cancer. Endocrinology 152: 2546-2551.

114. Arcidiacono B, Iiritano S, Nocera A, Possidente K, Nevolo MT, et al. (2012) Insulin resistance and cancer risk: an overview of the pathogenetic mechanisms. Exp Diabetes Res 2012: 789174.

115. Leinonen E, Hurt-Camejo E, Wiklund O, Hultén LM, et al. (2003) Insulin resistance and adiposity correlate with acute-phase reaction and soluble cell adhesion molecules in type 2 diabetes. Atherosclerosis 166: 387-394.

116. Aran D, Lasry A, Zinger A, Biton M, Pikarsky E, et al. (2016) Widespread parainflammation in human cancer. Genome Biol 17: 145.

117. Liu H, Heaney AP (2011) Refined fructose and cancer. Expert Opin Ther Targets 15: 1049-1059.

118. Krone CA, Ely JT (2005) Controlling hyperglycemia as an adjunct to cancer therapy. Integr Cancer Ther 4: 25-31.

119. Yang YX, Hennessy S, Lewis JD (2004) Insulin therapy and colorectal cancer risk among type 2 diabetes mellitus patients. Gastroenterology 127: $1044-1050$

120. Provinciali N, Puntoni M, Nanni O, Bruzzi P, DeCensi A, et al. (2015) Insulin resistance (IR) and prognosis of metastatic breast cancer (MBC) patients. The Breast 24: 66 .

121. Insel PA (1996) Adrenergic Receptors - Evolving Concepts and Clinical Implications. N Engl J Med 334: 580-585.

122. Schwartz RS, Jaeger LF, Veith RC (1988) Effect of clonidine on the thermic effect of feeding in humans. Am J Physiol 254: R90-R94.

123. Scott EM, Greenwood JP, Vacca G, Stoker JB, Gilbey SG, et al. (2002) Carbohydrate ingestion, with transient endogenous insulinemia produces both sympathetic activation and vasodilatation in normal humans. Clin Sci 102: 523-529.

124. Welle S, Ulavivat U, Campell G (1981) Thermic effect of feeding in men: Increased plasma norepinephrine levels following glucose but not protein or fat consumption. Metabolism 30: 953-958.

125. Tentolouris N, Tsigos C, Perea D, Koukou E, Kyriaki D, et al. (2003) Differential effect of high-fat and high-carbohydrate isoenergetic meals on cardiac autonomic nervous system activity in lean and obese women. Metabolism 52: 1426-1432.

126. Rowe JW, Young JB, Minaker KL, Stevens AL, Pallotta J, et al. (1981) Effect of insulin and glucose infusions on sympathetic nervous system activity in normal man. Diabetes 30: 219-225.
127. Minaker KL, Rowe JW, Young JB, Sparrow D, Pallotta JA, et al. (1982) Effect of age on insulin stimulation of sympathetic nervous system activity in man. Metabolism 31: 1181-1184

128. Anderson E, Hoffman P, Balon T, Sinkey C, Mark A, et al. (1991) Hyperinsulinemia produces both sympathetic neural activation and vasodilatation in normal humans. J Clin Invest 87: 2246-2252.

129. Scherrer U, Sartori C (1997) Insulin as a vascular and sympathoexcitatory hormone: implications for blood pressure regulation, insulin sensitivity, and cardiovascular morbidity. Circulation 96: 4104-4113.

130. Kopp W (2009) Chronically increased activity of the sympathetic nervous system: our diet-related "evolutionary" inheritance. J Nutr Health Aging 13: $27-29$.

131. Scherrer U, Owlya R, Lepori M (1996) Body fat and sympathetic nerve activity. Cardiovasc Drugs Ther 10: 215-222.

132. Tanga J, Lib Z, Lub L, Chob CH (2013) $\beta$-Adrenergic system, a backstage manipulator regulating tumour progression and drug target in cancer therapy. Semin Cancer Biol 23: 533-542.

133. Pimentel MA, Chai MG, Le CP, Le CP, Cole SW, et al. (2013) Sympathetic Nervous System Regulation of Metastasis. In: Madame Curie Bioscience Database. Austin (TX) Landes Bioscience 2: 2000-2013.

134. Fitzgerald PJ (2012) Beta blockers, norepinephrine, and cancer: an epidemiological viewpoint.Clin Epidemiol 4: 151-156.

135. Cole SW, Nagaraja AS, Lutgendorf SK, Paige A, Green PA, et al. (2015) Sympathetic nervous system regulation of the tumour microenvironment. Nat Rev Cancer 15: 563-572.

136. Kamide K, Hori MT, Zhu JH, Takagawa Y, Barrett JD, et al. (2000) Insulin and insulin-like growth factor-I promotes angiotensinogen production and growth in vascular smooth muscle cells. J Hypertens 18: 1051-1056.

137. Rakugi H, Kamide K, Ogihara (2002) Vascular signaling pathways in the metabolic syndrome. Curr Hypertens Rep 4: 105-111.

138. Young JB, Landsberg L (1997) Catecholamines and the regulation of hormone secretion. Clin 23 Endocrinol Metabol 6: 657-695.

139. Lavoie JL, Sigmund CD (2003) Minireview: Overview of the ReninAngiotensin System - An Endocrine and Paracrine System. Endocrinology 144: 2179-2183.

140. George AJ, Thomas WG, Hannan RD (2010) The renin-angiotensin system and cancer: old dog, new tricks. Nat Rev Cancer 10: 745-759.

141. Smith GR, Missailidis S (2004) Cancer, inflammation and the AT1 and AT2 receptors. J Inflamm 1: 3.

142. Deshayes F, Nahmias C (2005) Angiotensin receptors: a new role in cancer? Trends Endocrinol Metab 16: 293-299.

143. Wegman-Ostrosky T, Soto-Reyes E, Vidal-Millán S, Sánchez-Corona J (2015) The renin-angiotensin system meets the hallmarks of cancer. J Renin Angiotensin Aldosterone Syst 16: 227-233.

144. Imai N, Hashimoto T, Kihara M, Yoshida S, Kawana I, et al. (2007) Roles for host and tumor angiotensin II type 1 receptor in tumor growth and tumor-associated angiogenesis. Lab Invest 87: 189-198.

145. Park SY, Kang JH, Jeong KJ, Lee J, Han JW, et al. (2011) Norepinephrine induces VEGF expression and angiogenesis by a hypoxia-inducible factor-1 $\alpha$ protein-dependent mechanism. Int J Cancer 128: 2306-2316.

146. Fukuda R, Hirota K, Fan F, Jung YD, Ellis LM, et al. (2002) Insulin-like growth factor 1 induces hypoxia-inducible factor 1-mediated vascular endothelial growth factor expression, which is dependent on MAP kinase and phosphatidylinositol 3-kinase signaling in colon cancer cells. J Biol Chem 277: 205-211.

147. Hoeben A, Landuyt B, Highley MS, Wildiers H, Van Oosterom AT, et al. (2004) Vascular endothelial growth factor and angiogenesis. Pharm Rev 56: 549-580.

148. Sánchez-López E, López AF, Esteban V, Yagüe S, Egido J, et al. (2005) Angiotensin II regulates vascular endothelial growth factor via hypoxiainducible factor-1alpha induction and redox mechanisms in the kidney. Antioxid Redox Signal 7: 1275-1284.

149. Quintero M, Mackenzie N, Brennan PA (2004) Hypoxia-inducible factor 1 (HIF-1) in cancer. Eur J Surg Oncol 30: 465-468. 
150. Turrens JF (2003) Mitochondrial formation of reactive oxygen species. J Physiol 552: 335-344.

151. Trachootham D, Alexandre J, Huang P (2009) Targeting cancer cells by ROS-mediated mechanisms: a radical therapeutic approach? Nat Rev Drug Discov 8: 579-591.

152. Valle A, Oliver J, Roca P (2010) Role of Uncoupling Proteins in Cancer. Cancers (Basel) 2: 567-591.

153. Seoane M, Mosquera-Miguel A, Gonzalez T, Fraga M, Salas A, et al. (2011) The mitochondrial genome is a "genetic sanctuary" during the oncogenic process. PLoS One 6: e23327.

154. Kaniak-Golik A, Skoneczna A (2015) Mitochondria-nucleus network for genome stability. Free Radic Biol Med 82: 73-104.

155. Shigenaga MK, Hagen TM, Ames BN (1994) Oxidative damage and mitochondrial decay in aging. Proc Natl Acad Sci USA 91: 10771-10778.

156. Liesa M (2013) Mitochondrial Dynamics in the Regulation of Nutrient Utilization and Energy Expenditure. Cell Metab 17: 491-506.

157. Ayyasamy V, Owens KM, Desouki MM, Liang P, Bakin A, et al. (2011) Cellular model of Warburg effect identifies tumor promoting function of UCP2 in breast cancer and its suppression by genipin. PloS One 6: e24792.

158. Echtay KS, Roussel D, St-Pierre J, Jekabsons MB, Cadenas S, et al. (2002) Superoxide activates mitochondrial uncoupling proteins. Nature 415(6867): 96-99.

159. Brand MD, Affourtit C, Esteves TC, Green K, Lambert AJ, et al. (2004) Mitochondrial superoxide: production, biological effects, and activation of uncoupling proteins. Free Radic Biol Med 37: 755-767.

160. Krauss S, Zhang CY, Scorrano L, Dalgaard LT, St-Pierre J, et al. (2003) Superoxide-mediated activation of uncoupling protein 2 causes pancreatic beta cell dysfunction. J Clin Invest 112: 1831-1842.

161. Koziel A, Sobieraj I, Jarmuszkiewicz W (2015) Increased activity of mitochondrial uncoupling protein 2 improves stress resistance in cultured endothelial cells exposed in vitro to high glucose levels. Am J Physiol Heart Circ Physiol 309: H147-H156.

162. Chu KY, Leung PS (2007) Angiotensin II type 1 receptor antagonism mediates uncoupling protein 2-driven oxidative stress and ameliorates pancreatic islet beta-cell function in young type 2 diabetic mice. Antioxid Redox Signal 9: 869-878.

163. Fleury C, Neverova M, Collins S, Raimbault S, Champigny O, et al. (1997) Uncoupling protein-2: a novel gene linked to obesity and hyperinsulinemia. Nat Genet 15: 269-272.

164. Bouillaud F (2009) UCP2, not a physiologically relevant uncoupler but a glucose sparing switch impacting ROS production and glucose sensing. Biochim Biophys Acta 1787: 377-383.

165. Pecqueur C, Bui T, Gelly C, Hauchard J, Barbot C, et al. (2008) Uncoupling protein-2 controls proliferation by promoting fatty acid oxidation and limiting glycolysis-derived pyruvate utilization. FASEB J 22: 9-18.

166. Nubel T, Emre Y, Rabier D, Chadefaux B, Ricquier D, et al. (2008) Modified glutamine catabolism in macrophages of Ucp2 knock-out mice. Biochim Biophys Acta 1777: 48-54.

167. Zhang J, Khvorostov I, Hong JS, Oktay Y, Vergnes L, et al. (2011) UCP2 regulates energy metabolism and differentiation potential of human pluripotent stem cells. EMBO J 30: 4860-4873.

168. Varum S, Rodrigues AS, Moura MB, Momcilovic O, Easley CA IV, et al. (2011) Energy Metabolism in Human Pluripotent Stem Cells and Their Differentiated Counterparts. PLoS ONE 6: e20914.

169. Tohyama S, Fujita J, Hishiki T, Matsuura T, Hattori F, et al. (2016) Glutamine oxidation is indispensable for survival of human pluripotent stem cells. Cell Metab 23: 663-674.

170. Vozza A, Parisi G, De Leonardis P, Lasorsa FM, Castegna A, et al. (2014) UCP2 transports C4 metabolites out of mitochondria, regulating glucose and glutamine oxidation. Proc Natl Acad Sci 111: 960-965.

171. Zheng J (2012) Energy metabolism of cancer: Glycolysis versus oxidative phosphorylation (Review). Oncol Lett 4: 1151-1157.
172. DeBerardinis RJ, Lum JJ, Hatzivassiliou G, Thompson CB (2008) The biology of cancer: metabolic reprogramming fuels cell growth and proliferation. Cell Metab 7: 11-20.

173. Derdak Z, Mark NM, Beldi G, Robson SC, Wands JR, et al. (2008) The mitochondrial uncoupling protein-2 promotes chemoresistance in cancer cells. Cancer Res 68: 2813-2819.

174. Deng S, Yang Y, Han Y, Li X, Wang X, et al. (2012) UCP2 inhibits ROSmediated apoptosis in A549 under hypoxic conditions. PloS One 7: e30714.

175. Sayeed A, Meng Z, Luciani G, Chen LC, Bennington JL, et al. (2010) Negative regulation of UCP2 by TGF $\beta$ signaling characterizes low and intermediate-grade primary breast cancer. Cell Death Dis 1: e53.

176. Villee CA (1954) The intermediary metabolism of human fetal tissues. Cold Spring Harbor Symp Quant Biol 19: 186-199.

177. Pedersen PL, Mathupala S, Rempel A, Geschwind JF, Ko YH (2002) Mitochondrial bound type II hexokinase: a key player in the growth and survival of many cancers and an ideal prospect for therapeutic intervention. Biochim Biophys Acta 1555: 14-20.

178. Fan J, Kamphorst JJ, Mathew R, Chung MK, White E, et al. (2013) Glutamine-driven oxidative phosphorylation is a major ATP source in transformed mammalian cells in both normoxia and hypoxia. Mol Syst Biol 9: 712.

179. Carracedo A, Cantley LC, Pandolfi PP (2013) Cancer metabolism: fatty acid oxidation in the limelight. Nat Rev Cancer 13: 227-232.

180. Samudio I, Fiegl M, Andreeff M (2009) Mitochondrial uncoupling and the Warburg effect: Molecular basis for the reprogramming of cancer cell metabolism. Cancer Res 69: 2163-2166.

181. Uriel J (2015) Cell injury, retrodifferentiation and the cancer treatment paradox. Tumour Biol 36: 7365-7374.

182. Wicha MS, Liu S, Dontu G (2006) Cancer stem cells: an old idea--a paradigm shift. Cancer Res 66: 1883-1890.

183. Sell S (2008) Alpha-fetoprotein (AFP), stem cells and cancer: how the study of the production of AFP during chemical hepatocarcinogenesis led to reaffirmation of the stem cell theory of cancer. Tumour Biol 29: 161180.

184. Chaffer CL, Brueckmann I, Scheel C, Kaestli AJ, Wiggins PA, et al. (2011) Normal and neoplastic nonstem cells can spontaneously convert to a stem-like state. Proc Natl Acad Sci USA 108: 7950-7955.

185. Malaguarnera R, Belfiore A (2014) The Emerging Role of Insulin and Insulin-Like Growth Factor Signaling in Cancer Stem Cells. Front Endocrinol (Lausanne) 5: 10.

186. Prigione A, Rohwer N, Hoffmann S, Mlody B, Drews K, et al. (2014) HIF $1 \alpha$ modulates cell fate reprogramming through early glycolytic shift and upregulation of PDK1-3 and PKM2. Stem Cells 32: 364-376.

187. Veal EA, Day AM, Morgan BA (2007) Hydrogen peroxide sensing and signaling. Mol Cell 26: 1-14.

188. Finkel T (2011) Signal transduction by reactive oxygen species. J Cell Biol 194: 7-15.

189. Gough DR, Cotter TG (2011) Hydrogen peroxide: a Jekyll and Hyde signalling molecule. Cell Death Dis 2: e213.

190. Sauer H, Wartenberg M (2005) Reactive oxygen species as signaling molecules in cardiovascular differentiation of embryonic stem cells and tumor-induced angiogenesis. Antioxid Redox Signal 7: 1423-1434.

191. Sauer H, Wartenberg M, Hescheler J (2001) Reactive oxygen species as intracellular messengers during cell growth and differentiation. Cell Physiol Biochem 11: 173-186.

192. Salganik RI (2001) The benefits and hazards of antioxidants: controlling apoptosis and other protective mechanisms in cancer patients and the human population. J Am Coll Nutr 20: 464S-472S.

193. Lennicke C, Rahn J, Lichtenfels R, Wessjohann LA, Seliger B (2015) Hydrogen peroxide-production, fate and role in redox signaling of tumor cells. Cell Commun Signal 13: 39.

194. Zhou D, Shao L, Spitz DR (2014) Reactive Oxygen Species in Normal and Tumor Stem Cells. Adv Cancer Res 122: 1-67. 
Citation: Kopp W (2017) Significant Dietary Changes during Human Evolution and the Development of Cancer: From Cells in Trouble to Cells Causing Trouble. J Carcinog Mutagen 8: 303. doi:10.4172/2157-2518.1000303

Page 14 of 14

195. Sablina AA, Budanov AV, Ilyinskaya GV, Agapova LS, Kravchenko JE, et al. (2005) The antioxidant function of the p53 tumor suppressor. Nat Med 11: $1306-1313$.

196. Barrera G (2012) Oxidative stress and lipid peroxidation products in cancer progression and therapy. SRN Oncol 137: 289.

197. Liou GY, Storz P (2010) Reactive oxygen species in cancer. Free Radic Res 44: 5.

198. Schieber M, Chandel NS (2014) ROS function in redox signaling and oxidative stress. Curr Biol 24: R453-462.

199. Sell S, Pierce GB (1994) Biology of Disease: Maturation arrest of stem cell differentiation is a common pathway for the cellular origin of teratocarcinomas and epithelial cancers. Lab Invest 70: 6-21.

200. Sell S (1993) Cellular origin of cancer: dedifferentiation or stem cell maturation arrest? Environ Health Perspect 101: 15-26

201. McMurray F, Patten DA, Harper ME (2016) Reactive Oxygen Species and Oxidative Stress in Obesity-Recent Findings and Empirical Approaches. Obesity (Silver Spring) 24: 2301-2310.

202. Han CY (2016) Roles of reactive oxygen species on insulin resistance in adipose tissue. Diabetes Metab J 40: 272-279.

203. Muoio DM (2014) Metabolic Inflexibility: When mitochondrial indecision leads to metabolic gridlock. Cell 159: 1253-1262.

204. Bournat JC, Brown CW (2010) Mitochondrial Dysfunction in Obesity. Curr Opin Endocrinol Diabet Obes 17: 446-452.

205. Alberts B, Bray D, Johnson A, Lewis J, Raff M, et al. (2008) How Cells Obtain Energy from Food. In: Essential Cell Biology. An Introduction to the Molecular Biology of the Cell. Garland Publishing Inc, New York, London. pp: 107-131.

206. Randle PJ, Garland PB, Hales CN, Newsholme EA (1963) The glucose fatty-acid cycle its role in insulin sensitivity and the metabolic disturbances of diabetes mellitus. The Lancet 281: 785-789.

207. Havel RJ, Goldfien A (1959) The role of the sympathetic nervous system in the metabolism of free fatty acids? J Lipid Res 1: 102-108.

208. Koves TR, Ussher JR, Noland RC, Slentz D, Mosedale M, et al. (2008) Mitochondrial overload and incomplete fatty acid oxidation contribute to skeletal muscle insulin resistance. Cell Metab 7: 45-56.

209. Jebb SA (2005) Dietary strategies for the prevention of obesity. Proc Nutr Soc 64: 217-227.

210. Korshunov SS, Skulachev VP, Starkov AA (1997) High protonic potential actuates a mechanism of production of reactive oxygen species in mitochondria. FEBS Lett 416: 15-18.

211. Murphy MP (2009) How mitochondria produce reactive oxygen species. Biochem J 417: 1-13.

212. Cui Y, Xu X, Bi H, Zhu Q, Wu J, et al. (2006) Expression modification of uncoupling proteins and MnSOD in retinal endothelial cells and pericytes induced by high glucose: the role of reactive oxygen species in diabetic retinopathy. Exp Eye Res 83: 807-816.

213. Twig G, Elorza A, Molina AJ, Mohamed H, Wikstrom JD, et al. (2008) Fission and selective fusion govern mitochondrial segregation and elimination by autophagy. EMBO J 27: 433-446.

214. Yu T, Robotham JL, Yoon Y (2006) Increased production of reactive oxygen species in hyperglycemic conditions requires dynamic changes of mitochondrial morphology. Proc Natl Acad Sci USA 103: 2653-2658.

215. Wellen KE, Thompson CB (2010) Cellular metabolic stress: Considering how cells respond to nutrient excess. Mol Cell 40: 323-332.

216. Wang $\mathrm{CH}, \mathrm{Wu} \mathrm{SB}, \mathrm{Wu} \mathrm{YT}$, Wei $\mathrm{YH}$ (2013) Oxidative stress response elicited by mitochondrial dysfunction: implication in the pathophysiology of aging. Exp Biol Med (Maywood) 238: 450-460.

217. Seals DR, Esler MD (2000) Human ageing and the sympathoadrenal system. J Physiol 528: 407-417.

218. Holloszy JO, Khort WM (1995) Ageing: exercise. In: Handbook of Physiology. Masoro EJ, Ed. Oxford University Press, New York. pp: 633-666.

219. Chavin KD, Yang S, Lin HZ, Chatham J, Chacko VP, et al. (1999) Obesity induces expression of uncoupling protein-2 in hepatocytes and promotes liver ATP depletion. J Biol Chem 274: 5692-5700.

220. Davy KP, Orr JS (2009) Sympathetic nervous system behavior in human obesity. Neurosci Biobehav Rev 33: 116-124.

221. Puddu P, Puddu GM, Cravero E, De Pascalis S, Muscari A (2009) The emerging role of cardiovascular risk factor-induced mitochondrial dysfunction in atherogenesis. J Biomed Sci 16: 112.

222. Yoshida T, Yoshioka K, Wakabayashi Y, Kondo M (1989) Effects of cigarette smoke on norepinephrine turnover and thermogenesis in brown adipose tissue in MSG-induced obese mice. Endocrinol Jpn 36: 537-544.

223. Bajaj M (2012) Nicotine and Insulin Resistance: When the Smoke Clears. Diabetes 61: 3078-3080.

224. Mouhamed D, Ezzaher A, Neffati F, Douki W, Gaha L, et al. (2016) Effect of cigarettesmoking on insulin resistance risk. Ann Cardiol Angeiol (Paris) 65: 21-25.

225. Orsolya KO, Guanyu GG, Olipitz W, Muthupalani S, Engelward BP (2015) Inflammation-Induced cell proliferation potentiates DNA damage-induced mutations in vivo. PLoS Genet 11: e1004901.

226. Stelios TS, Tsatsoulis A (2012) Endocrine and metabolic manifestations in inflammatory bowel disease. Ann Gastroenterol 25: 37-44.

227. Schwarz KB (1996) Oxidative stress during viral infection: a review. Free Radic Biol Med 21: 641-649.

228. De Marco F (2013) Oxidative stress and HPV carcinogenesis. Viruses 5: 708-731. 